\title{
Disentangling the lumbar PIVD puzzle: A narrative review
}

\author{
Varun Singh, Manoj Malik, Jaspreet Kaur, Sonu Punia \\ Department of Physiotherapy, Guru Jambheshwar University of Science and Technology, Hisar, India
}

\begin{abstract}
Lumbar prolapse intervertebral disc (PIVD) is a common back related disability throughout the world. It is one of common cause for work absenteeism and pose high economic burden on society. Till date, the etiology of lumbar PIVD has not been clearly established. Mechanical compression and chemical irritation are the major pathophysiological changes in lumbar PIVD. The accurate diagnosis of lumbar PIVD is a prerequisite for appropriate therapy. Lumbar PIVD results in significant disability and loss of productivity. Therefore, it is pertinent to summarize the intricacies and nuances of Lumbar PIVD as well as its evidence based management. Various cost effective and time saving protocols are available in surgical and non-surgical management of lumbar PIVD. In the present review, an attempt has been made to highlight etiology, underlying pathophysiological mechanisms of lumbar PIVD, as well as evidence based management of lumbar PIVD.
\end{abstract}

Keywords: lumbar prolapsed intervertebral disc, diagnosis, pathophysiology, management

\section{INTRODUCTION}

Lumbar prolapsed intervertebral disc is one of most common spinal problem in both men and women across the world. It causes significant disability as well as economic burden [1,2]. Lumbar disc undergoes axial loading, bending and shear forces. These forces may result in disc prolapse. Avascular nature of disc further adds to this vulnerability [3]. Pain from a prolapsed lumbar disc can vary, depending on level and severity of disc prolapse. Mechanical compression or chemical irritation of lumbar nerve root typically produces pain on one side of body [3]. After lumbar disc prolapse, if pain and numbness persists, it may require surgical intervention. Lumbar disc prolapse can be managed by various means ranging from simple bed rest to endoscopic micro-discectomy. Early diagnosis along with proper management leads to better outcome [4]. Most of the cases recover in 12 weeks. Conservative treatment is recommended to decrease pain and disability.
Patient may need to undergo surgery. Failure of conservative treatment and progressive neurological deficit or cauda equina syndrome are indications of Surgery [5].

\section{ANATOMY OF THE INTERVERTEBRAL DISC}

Disc is made of three components: cartilaginous endplates, annulus fibrosus (AF), and nucleus pulposus (NP). Peripheral part of disc is annulus fibrosus while nucleus pulposus is the central one. The cartilaginous end plates are located on bodies of adjacent vertebra. The annulus fibrosus has a unique multilayer structure made up of collagen type I, type II fibers and proteoglycans, each layer oriented at $30^{\circ}$ to horizontal and successive layer in opposite direction in such a way that leads to a criss-cross pattern. Such unique structure gives the annulus more tensile modulus against torsional, axial, and tensile loads [3]. Nucleus pulposus contains approximately $70 \%$ water, notochordal cells along with fibroblast and chondrocyte like cells. Noto- 
chordal cells stimulate collagen and proteoglycans production and control apoptosis of chondrocyte like cells [6]. Hydrostatic pressure is generated in disc due to imbibed water. Hydrophilic proteoglycan macro-molecules of nucleus pulposus make a unique composition within collagen matrix. It is encircled by annulus peripherally and end plates above and below. The nucleus pulposus provides resistance to axial compression. The endplates are composed of mainly of water followed by chondrocytes, proteoglycans (PGs), and type II collagen. Capillary network of cartilaginous layer may extend into the outer portions of annular fibrosus upto a short distance that provide nourishment to otherwise avascular disc [7]. Nutrition of disc cells occurs via diffusion through the vertebral end plates. Disc is poorly innervated. Normally, nucleus pulposus and inner annulus fibrosus has no innervations. However, outer annulus fibrosis is innervated [3].

\section{DISC PROLAPSE OR HERNIATION}

As per combined statement of the North American Spine Society, the American Society of Spine Radiology, and the American Society of Neuroradiology, disc herniation can be defined as "localized or focal displacement of disc material beyond the limits of the intervertebral disc space". Almost three fourth cases of disc pathology are of degeneration and one fourth are actual disc herniation [8]. Herniated discs can be classified as "protrusion", "extrusion", or "sequestration". Protrusion is focal bulging of disc than diameter in have wider based herniations canal. In Extrusion, nucleus pulposus ruptures through annulus with a smaller base and larger herniation in the canal. In sequestration, disc has migrated away and no contact between herniated part and the remaining disc [8].

\section{EPIDEMIOLOGY}

There are a number of risk factors that may contribute to lumbar PIVD. Lumbar disc herniation is more common in males and an average age of 41 years [9]. Bostman found that in Finland, $27 \%$ of patients who underwent a lumbar disc surgery were obese, whereas at same time obesity prevalence was only $16 \%$ among population of Finland. Overweight and obese patients are more prone to lumbar radiculopathy as compared to Non-obese people [9]. Obese persons are thirty times more prone to re-operation after microdiscectomy [10]. Mobbs et al. stated that reoperation for lumbar PIVD in diabetics is more frequent as compared to non-diabetics [10]. Due to some comorbidities, impaired microcirculation of disc increases the chances of lumbar PIVD. Certain occupations may be a cause for lumbar PIVD. Most commonly affected level is L4-L5 [4]. Twisting mechanism in combination with axial load or flexion with axial load can be a biomechanics of lumbar PIVD [11]. In a retrospective study Alpesh et al. [12] support an inheritable predisposition of lumbar disc herniation [12]. Lumbar disc herniation is multifactorial, including contributions from mechanical stresses to the spine, age-dependent disc degeneration, biochemical factors and genetics.

\section{PATHOPHYSIOLOGY}

Natural degenerative changes in intervertebral disc include decrease in number of capillaries, altered cell morphology and density of nucleus pulposus. Annular clefts and apoptosis of fibroblast-like cells are increased in intervertebral disc [13]. Disc herniation is categorized in three steps: protrusion, extrusion and sequestration (Figure 1). Mechanical compression is commonly considered as cause of radiculopathy. Nerve roots are composed of endoneurium similar to peripheral nerve while cerebrospinal fluid and dural lining are present instead of perineurium and epineurium respectively. Such type of structure make nerve root soft and prone to get compressed mechanically. Nerve roots are in close approximation to vertebral bodies. Disc herniation exerts tensile force on nerve root similar to bowstring effect. Nutrition is impaired in mechanically compressed nerve root as both blood flow and nutrient diffusion are compromised. Intraneural edema, nerve fibrosis and injury may lead to compartment syndrome in mechanically compressed nerve. A large number of studies conclude that mechanical effect is main contributing factor in radiculopathy, while some studies claims that chemical irritation along with mechanical compression are responsible for radiculopathy in lumbar PIVD [14]. Disc herniation can be seen in magnetic resonance imaging (Figure 2). On the basis of magnetic resonance imaging, it can be in- 
ferred that compression of nerve root is mostly asymptomatic. According to a study, 20\% of asymptomatic participants of age below 60 years

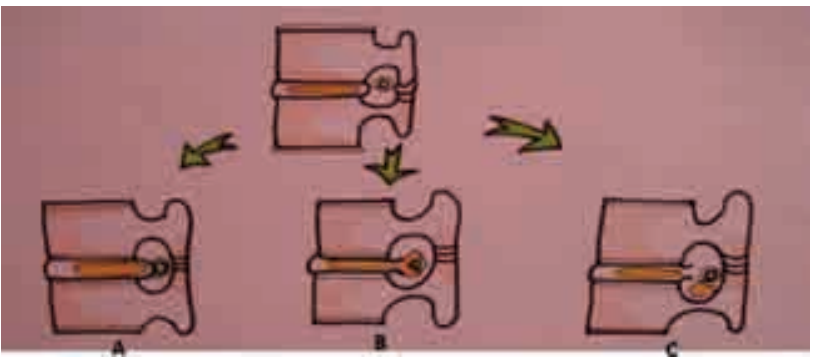

FIGURE 1. Classification of lumbar disc herniation. A. Protrusion; B. Extrusion; C. Sequestration and $36 \%$ of participants of age above 60 years have radiological evidences of disc herniation. It is

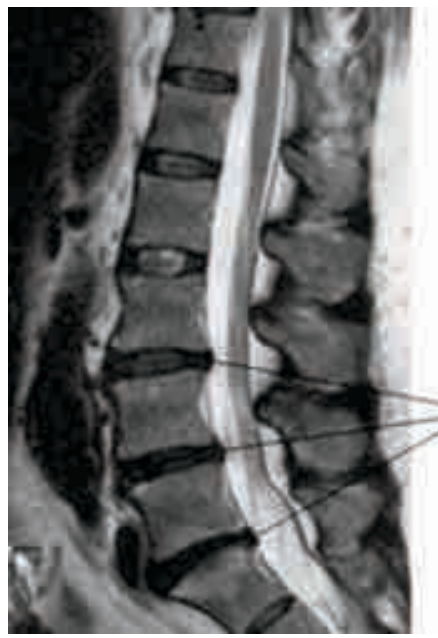

Disc

herniation

FIGURE 2. MRI of

lumbar disc herniation

Degenerative changes in intervertebral disc

(Decrease in no. of capillaries, altered density of nucleus pulposus)

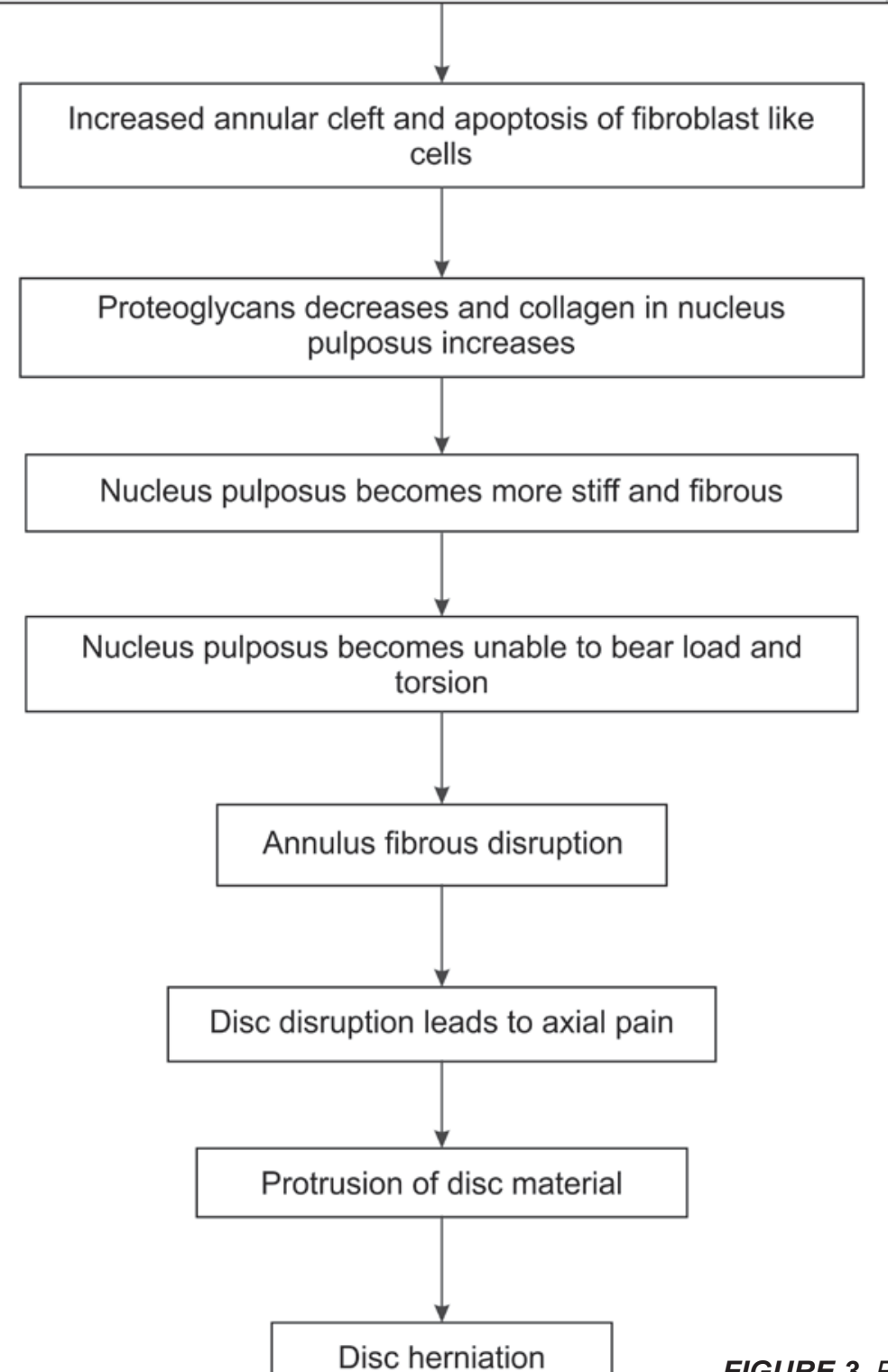

Disc herniation 
claimed that irritated nerve root are more prone to mechanical compression as compared to normal nerve roots [14]. Some bioactive molecules found in nucleus pulposus like interleukins, tumor necrosis factor-(TNF) alpha and some other factors are responsible for nerve root sensitization making it prone to mechanical compression [15]. TNF-alpha can be the factor responsible for decrease in nerve conduction velocity. The pathophysiology of lumbar disc herniation has been summarized in Figure 3.

\section{CLINICAL PRESENTATION}

Radiating pain, abnormal sensation and weakness in area of lumbosacral nerve roots in lower limb are primary clinical presentations of lumbar disc herniation [16]. There may be localized paresis, coldness in leg, limited trunk flexion, exacerbation in pain with sneezing, straining and coughing [16]. Patients complain difficulty in sitting, as it increases disc pressure upto $40 \%$ as compared to upright standing [17]. Forward flexion also contributes to increase in pain as the pressure on lumbar disc is increased by 100-400\% [17]. So lumbar disc prolapse induces radiating pain, abnormal sensation, weakness, paresis, cold leg, limited range of motion and difficulty in sitting.

\section{DIAGNOSTIC GUIDELINES}

Initial screening for diagnosis can be done by straight leg raise (SLR) test along with Hancock rule $[18,19]$. Three symptoms should be positive out of following four: pain along dermatome, abnormal reflex, motor weakness and sensory deficits [18]. Importance and validity of negative SLR test in clinical diagnosis is supported by a number of studies, irrespective of level of involvement [20-22]. Importance of crossed SLR tests for clinical diagnosis is also supported by a number of studies [20-22]. Various imaging tools are used to confirm the diagnosis.

\section{Radiographic imaging}

Radiograph is an important tool used to screen patients for diagnosis. Flexion and extension views may also be helpful along with antero-posterior (AP) and lateral views. Radiographs show compensatory scoliosis, osteophytes and reduced intervertebral space in lumbar disc prolapse.

\section{Magnetic resonance imaging}

Magnetic resonance imaging (MRI) is used as a gold standard tool for confirmation of lumbar disc prolapse due to its high inter-observer reliability and $97 \%$ accuracy [23].

\section{Computed tomography scan}

Computed tomography scan (CT-Scan) is also an important diagnostic tool. Clinical importance of CT-Scan is supported by a number of studies [24]. It can be used as alternative tool to MRI for suspected cases.

\section{TREATMENT}

Characteristics of major included studies are summarized in Table1. Treatment is broadly classified into operative and non-operative management. Non-operative management is further sub classified as pharmacological and non-pharmacological management.

\section{Non-operative management}

Non-operative management for lumbar disc prolapse is first choice of treatment in majority of cases. Conservative and surgical procedures both are equally effective outcomes at midterm and long term [25]. Conservative management for lumbar disc prolapse consists of non-steroidal anti-inflammatory drugs (NSAIDs), steroids, acupuncture, core exercise, taping, ergonomic advise and Physiotherapy [26-29]. Non-steroidal anti-inflammatory drugs and pregabalin are most commonly used agents and have different clinical impact [30]. A variety of lumbar epidural injections are used clinically [31-36]. However, effectiveness of such injections varies from $20-95 \%$ decrease in pain on long term follow up. Trans-foraminal injections give better result than caudal or interlaminar technique [36]. Position of patient during epidural injection can also affect the success of treatment. Decubitus position during epidural injection gives better outcome at 6 month and 12 month as compared to prone position [37]. Outcomes of epidural injections can be predicted by radiologic evaluation [38]. Epidural and subcutaneous injection of TNF- $\alpha$ inhibitors are effective in clinical improvement [39]. 


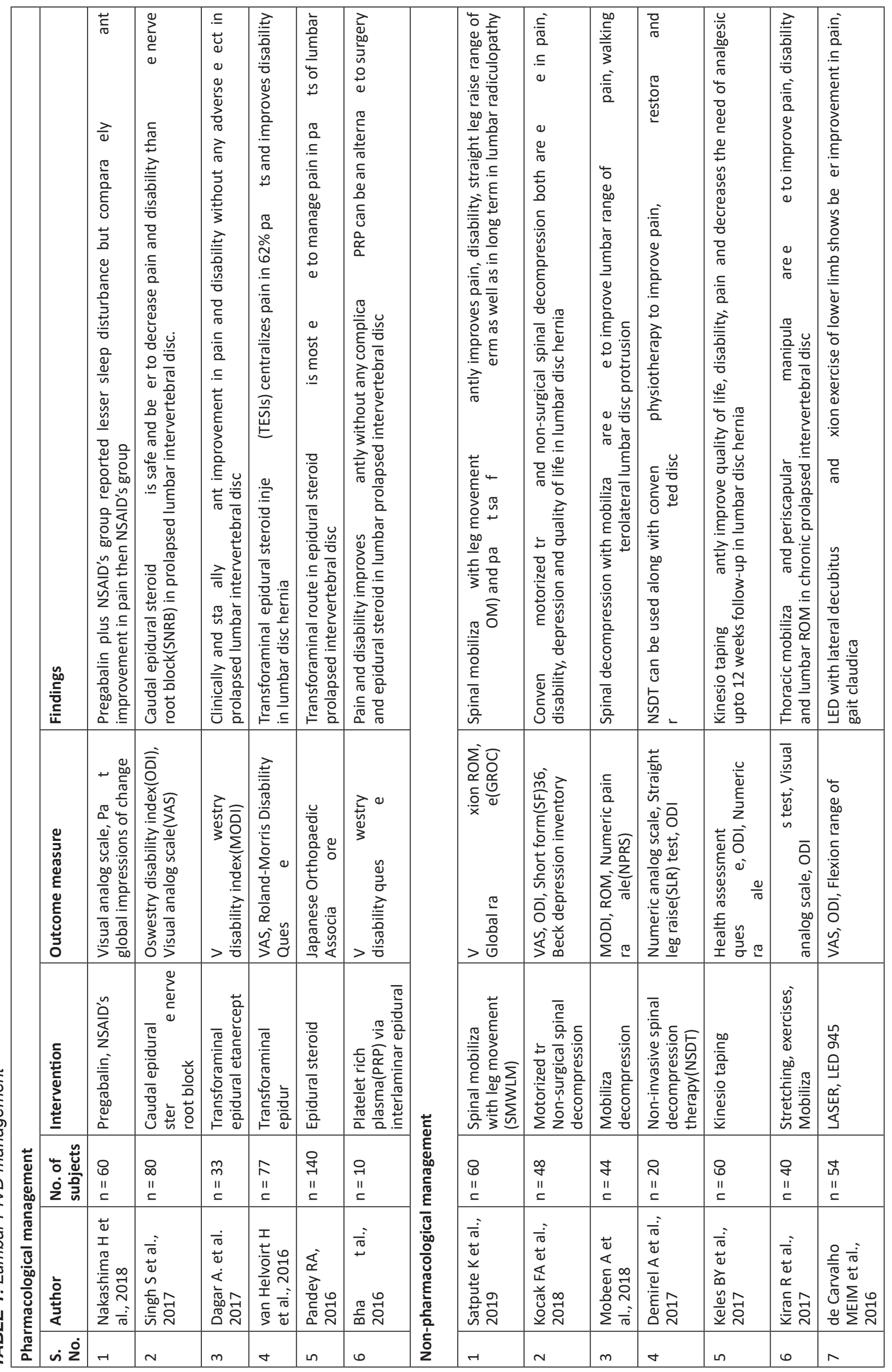




\begin{tabular}{|c|c|c|c|c|c|c|c|}
\hline 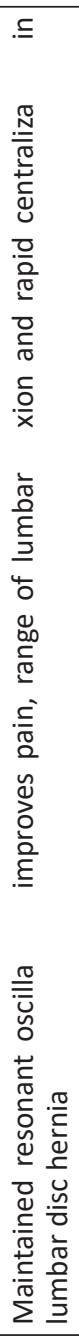 & 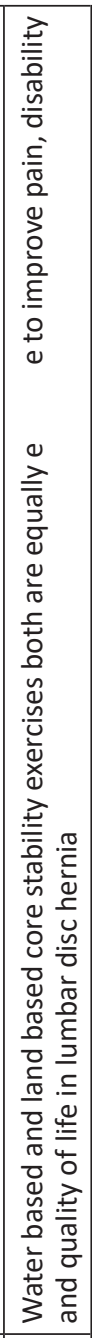 & & 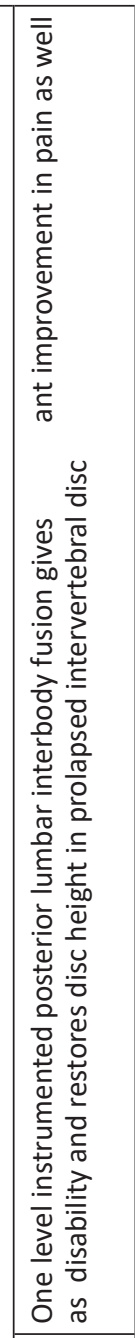 & 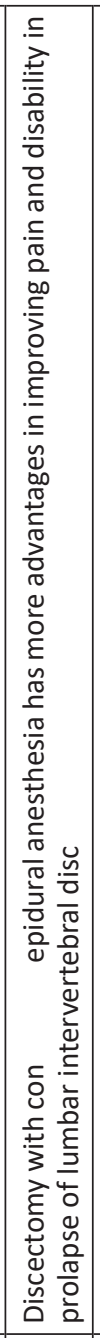 & 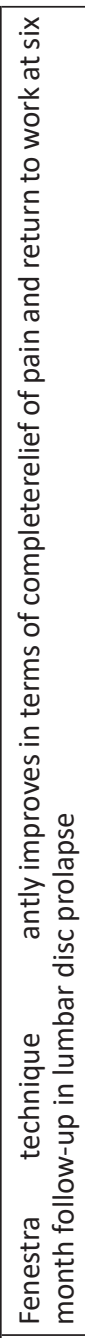 & 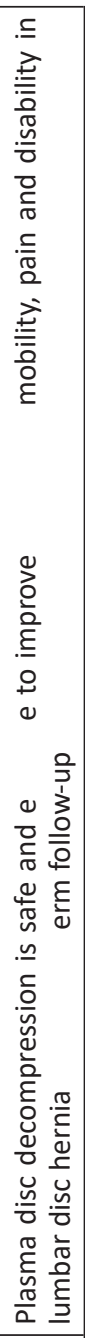 & 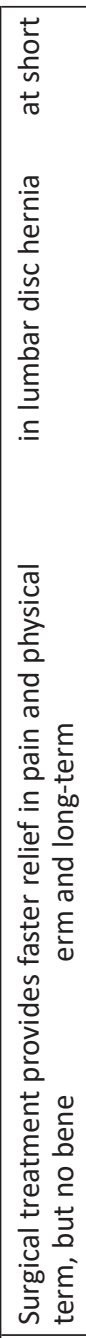 \\
\hline 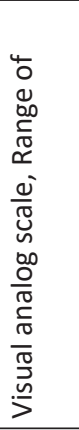 & 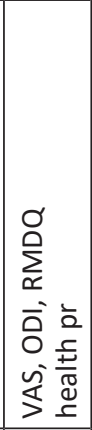 & \multirow{5}{*}{ 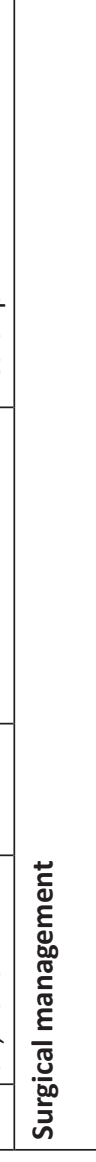 } & 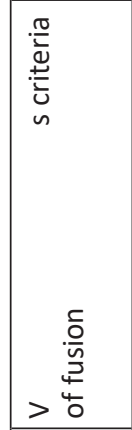 & $\begin{array}{l}\overline{0} \\
\bar{s} \\
\bar{s}\end{array}$ & 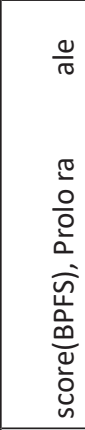 & 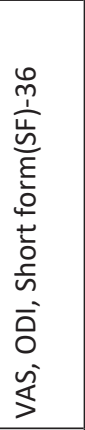 & 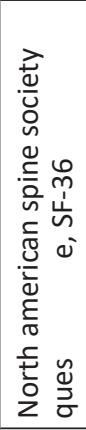 \\
\hline 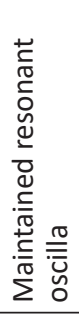 & 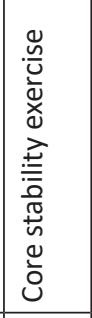 & & 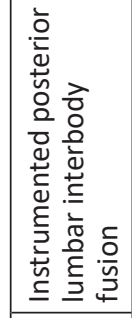 & 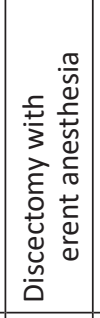 & 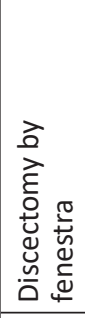 & 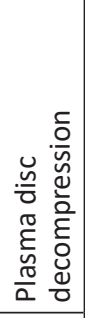 & 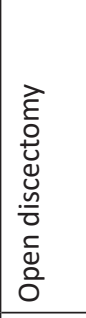 \\
\hline $\begin{array}{l}\stackrel{0}{m} \\
11 \\
=\end{array}$ & $\begin{array}{l}-1 \\
n \\
11 \\
=\end{array}$ & & $\begin{array}{l}J \\
I \\
I 1\end{array}$ & $\begin{array}{l}\alpha \\
\text { N } \\
\text { II }\end{array}$ & $\begin{array}{l}0 \\
\text { in } \\
\text { II }\end{array}$ & $\begin{array}{l}\text { ᄀ1 } \\
\text { II }\end{array}$ & $\begin{array}{l}\stackrel{P}{2} \\
m \\
11 \\
ᄃ\end{array}$ \\
\hline 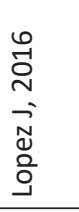 & 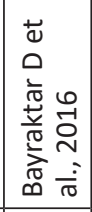 & & 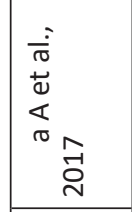 & 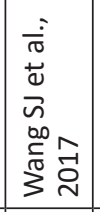 & 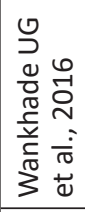 & 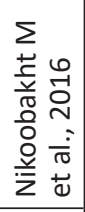 & 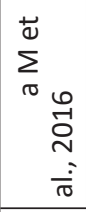 \\
\hline$\infty$ & $a$ & & $r$ & 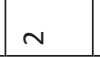 & $m$ & & in \\
\hline
\end{tabular}


Shin et al. concluded the combined effect of multiple therapies including acupuncture, bee-venom pharmacopuncture, herbal supplementation and spinal manipulation are effective in long term to improve VAS as well as ODI score [40]. Spontaneous resorption is also possible [41]. Traction and spinal decompression is also effective in decreasing disability and VAS score [42-45]. Joint mobilization, core training and active exercises are effective in improving recovery outcomes in lumbar disc prolapse [46-48]. Mesenchymal stem cell (MSC) therapy and platelet rich plasma (PRP) injection are also used clinically nowadays. Studies corroborate clinical improvement in ODI and VAS score without any complications [49-52].

\section{Operative treatment}

Surgical management is beneficial in short term as compared to non-operative management. However, in mid to long term both have no significant differences [25].

\section{Minimal invasive surgery}

Such type of intervention leads to less soft tissue lesion, reduced hospital stay and early joining back to work [53]. Trans-foraminal, trans-iliac, inter-laminar and posterolateral are few percutaneous endoscopic minimal invasive approach used commonly for spine surgery [54-56]. These interventions are associated with reduced blood loss, re-operation rate, operative time and other complications as compared to open procedure [57].

\section{Other surgical procedure}

Discectomy, instrumental posterior lumbar interbody fusion, dynamic stabilization with nucle- otomy and plasma disc decompression are used having significant results $[58,59]$. Previously discectomy was used as a gold standard surgical procedure in lumbar disc prolapse. Discectomy procedure has a number of complications like dural tear, postoperative infection; nerve root injury and increased hospital stay [60-62]. Recent meta-analysis shows advantages of microdiscectomy over open discectomy, such as shorter hospital stay and reducing initial post-operative pain. Rongqing et al. [63] stated that percutaneous endoscopic lumbar discectomy showed shorter hospital stay and time of return to work [63].

\section{CONCLUSIONS}

Lumbar disc is almost avascular. It has small regenerative ability and bears significant axial load. Multidirectional movements along with rotational forces and axial loads commonly lead to lumbar disc herniations that may be associated with radiculopathy. Proper and accurate diagnosis for assessment of level involved, severity of compression and neurological involvement can be assessed by clinical examination, patient history assisted by radiological evidences of magnetic resonance imaging (MRI) and computed tomography scanning (CT-scan) etc. There are number of interventions including conservative and surgical approaches that are used for management of lumbar PIVD. Authors opine that for an effective and evidence based practice, attention of the therapist should be focused on the biomechanics of lumbar PIVD and specific biochemical factors that leads to pain, disability and other associated complications due to lumbar PIVD.

\section{REFERENCES}

1. Deyo RA, Mirza SK. Herniated lumbar intervertebral disk. N Engl J Med. 2016;374:1763-72.

2. Ademi Z, Gloy V, Glinz D et al. Cost-effectiveness of primarily surgical versus primarily conservative treatment of acute and subacute radiculopathies due to intervertebral disc herniation from the Swiss perspective. Swiss Med Wkly. 2016;146:w14382.

3. Rhee JM, Schaufele M, Abdu WA. Radiculopathy and the herniated lumbar disc. J Bone Jt Surg. 2006;88:2069-80.

4. Sarma P, Thirupathi RT, Srinivas D et al. Adolescent prolapsed lumbar intervertebral disc: Management strategies and outcome. J Pediatr Neurosci. 2016;11:20-24.

5. Gadiya A, Borde M, Patel P et al. Lumbar prolapsed intervertebral disc - a treatment algorithm. J Clin Orthopaedics. 2016;1:29-35.

6. Erwin WM, Islam D, Inman RD et al. Notochordal cells protect nucleus pulposus cells from degradation and apoptosis: implications

for the mechanisms of intervertebral disc degeneration. Arthritis Res Ther. 2011;13:R215.

7. Taylor JR. Growth of human intervertebral discs and vertebral bodies. J Anat. 1975;120:49-68.

8. Fardon DF, Williams AL, Dohring EJ et al. Lumbar disc nomenclature: version 2.0: Recommendations of the combined task forces of the North American Spine Society, the American Society of Spine Radiology and the American Society of Neuroradiology. Spine J. 2014;14:2525-45.

9. Weiler C, Lopez-Ramos M, Mayer HM et al. Histological analysis of surgical lumbar intervertebral disc tissue provides evidence for an association between disc degeneration and increased body mass index. BMC Res Notes. 2011;4:497.

10. Meredith DS, Huang RC, Nguyen J et al. Obesity increases the risk of recurrent herniated nucleus pulposus after lumbar microdiscectomy. Spine J. 2010;10:575-80. 
11. Schroeder GD, Guyre CA, Vaccaro AR. The epidemiology and pathophysiology of lumbar disc herniations. Semin Spine Surg. 2016;28:2-7.

12. Patel AA, Spiker WR, Daubs $M$ et al. Evidence for an inherited predisposition to lumbar disc disease. J Bone Jt Surg - Ser A. 2011;93(3):225-29.

13. Boos $\mathrm{N}$, Weissbach $\mathrm{S}$, Rohrbach $\mathrm{H}$ et al. Classification of agerelated changes in lumbar intervertebral discs: 2002 Volvo award in basic science. Spine (Phila Pa 1976). 2002;27:2631-44.

14. Kuslich SD, Ulstrom CL MC. The tissue origin of low back pain and sciatica: a report of pain response to tissue stimulation during operations on the lumbar spine using local anesthesia. Orthop Clin North Am. 1991;22:181-87.

15. Miyamoto H, Saura R, Doita M et al. The role of cyclooxygenase-2 in lumbar disc herniation. Spine (Phila Pa 1976). 2002;27:2477-83.

16. Vroomen PC, De Krom MC, Wilmink JT et al. Diagnostic value of history and physical examination in patients suspected of lumbosacral nerve root compression. J Neurol Neurosurg Psychiatry. 2002;72(5):630-34.

17. Nachemson AL. Disc pressure measurements. Vol. 6, Spine. 1981. p. 93-97.

18. Petersen T, Laslett M, Juhl C. Clinical classification in low back pain: best-evidence diagnostic rules based on systematic reviews. BMC Musculoskelet Disord. 2017;18:188.

19. Luchtmann M, Firsching R. Lumbar disc herniation. The Indian Practitioner. 2016;69:36-41.

20. Kerr RS, Cadoux-Hudson TA, Adams CB. The value of accurate clinical assessment in the surgical management of the lumbar disc protrusion. J Neurol Neurosurg Psychiatry. 1988;51:169-73.

21. Knutsson B. Comparative Value of Electromyographic, Myelographic and Clinical-Neurological Examinations in Diagnosis of Lumbar Root Compression Syndrome. Acta Orthop Scand. 1961;32(sup49):3-135.

22. Spangfort EV. The Lumbar Disc Herniation: A Computer-Aided Analysis of 2,504 Operations. Acta Orthop Scand. 1972; 43(sup142):1-99.

23. Messner A, Stelzeneder D, Trattnig S et al. Does T2 mapping of the posterior annulus fibrosus indicate the presence of lumbar intervertebral disc herniation? A 3.0 Tesla magnetic resonance study. Eur Spine J. 2017;26:877-83.

24. Notohamiprodjo S, Stahl R, Braunagel M et al. Diagnostic accuracy of contemporary multidetector computed tomography (MDCT) for the detection of lumbar disc herniation. Eur Radiol. 2017;27:3443-51.

25. Gugliotta M, da Costa BR, Dabis E et al. Surgical versus conservative treatment for lumbar disc herniation: a prospective cohort study. BMJ Open. 2016;6:e12938.

26. de Carvalho ME, de Carvalho RM Jr, Marques AP et al. Low intensity laser and LED therapies associated with lateral decubitus position and flexion exercises of the lower limbs in patients with lumbar disk herniation: clinical randomized trial. Lasers Med Sci. 2016;31:1455-63.

27. Wong JJ, Côté P, Sutton DA et al. Clinical practice guidelines for the noninvasive management of low back pain: A systematic review by the Ontario Protocol for Traffic Injury Management (OPTIMa) Collaboration. Eur J Pain. 2017;21:201-16.

28. Keles BY, Yalcinkaya EY, Gunduz B et al. Kinesio Taping in patients with lumbar disc herniation: A randomised, controlled, double-blind study. J Back Musculoskelet Rehabil. 2017;30:543-50.

29. Bayraktar D, Guclu-Gunduz A, Lambeck J et al. A comparison of water-based and land-based core stability exercises in patients with lumbar disc herniation: A pilot study. Disabil Rehabil. 2016;38:1163-71.

30. Nakashima H, Kanemura T, Ando K et al. Is Pregabalin Effective Against Acute Lumbar Radicular Pain? Spine Surg Relat Res. 2018;

31. Manchikanti L, Pampati V, Benyamin RM et al. Cost utility analysis of lumbar interlaminar epidural injections in the treatment of lumbar disc herniation, central spinal stenosis, and axial or discogenic low back pain. Pain Physician. 2017;20:219-28.

32. van Helvoirt $\mathrm{H}$, Apeldoorn AT, Knol DL et al. Transforaminal epidural steroid injections influence Mechanical Diagnosis and Therapy (MDT) pain response classification in candidates for lumbar herniated disc surgery. J Back Musculoskelet Rehabil. 2016;29:351-59.
33. Bhatia R, Chopra G. Efficacy of Platelet Rich Plasma via Lumbar Epidural Route in Chronic Prolapsed Intervertebral Disc Patients-A Pilot Study. J Clin Diagnostic Res. 2016;10:5-7.

34. Dagar A, Kumar R, Kashyap A et al. Journal of clinical orthopaedics and trauma transforaminal epidural etanercept for the treatment of prolapsed lumbar intervertebral disc induced sciatica. J Clin Orthop Trauma. 2017;8:148-52.

35. Singh S, Kumar S, Chahal G et al. Selective nerve root blocks vs. caudal epidural injection for single level prolapsed lumbar intervertebral disc - A prospective randomized study. J Clin Orthop Trauma. 2017;8(2):142-47.

36. Pandey RA. Efficacy of epidural steroid injection in management of lumbar prolapsed intervertebral disc: A comparison of caudal, transforaminal and interlaminar routes. J Clin Diagnostic Res JCDR. 2016;10:5-11.

37. Altun I, Yuksel KZ. Impact of position on efficacy of caudal epidural injection for low back pain and radicular leg pain due to central spinal stenosis and lumbar disc hernia. J Korean Neurosurg Soc. 2017;60:205-10.

38. Kim J, Hur JW, Lee JB et al. Surgery versus nerve blocks for lumbar disc herniation: quantitative analysis of radiological factors as a predictor for successful outcomes. J Korean Neurosurg Soc. 2016;59:478-84.

39. Freeman BJ, Ludbrook GL, Hall S et al. Randomized, double-blind, placebo-controlled, trial of transforaminal epidural etanercept for the treatment of symptomatic lumbar disc herniation. Spine (Phila $\mathrm{Pa}$ 1976). 2013;38:1986-94.

40. Shin JS, Lee J, Lee YJ et al. Long-term course of alternative and integrative therapy for lumbar disc herniation and risk factors for surgery: a prospective observational 5-year follow-up study. Spine (Phila Pa 1976). 2016;41:E955-63.

41. Zhong M, Liu JT, Jiang $H$ et al. Incidence of spontaneous resorption of lumbar disc herniation: a meta-analysis. Pain Physician. 2017;20:E45-52.

42. Isner-Horobeti ME, Dufour SP, Schaeffer M et al. High-force versus low-force lumbar traction in acute lumbar sciatica due to disc herniation: a preliminary randomized trial. J Manipulative Physiol Ther. 2016;39:645-54.

43. Demirel A, Yorubulut M, Ergun N. Regression of lumbar disc herniation by physiotherapy. Does non-surgical spinal decompression therapy make a difference? Double-blind randomized controlled trial. J Back Musculoskelet Rehabil. 2017;30:1015-22.

44. Koçak FA, Tunç $H$, Sütbeyaz ST et al. Comparison of the short-term effects of the conventional motorized traction with non-surgical spinal decompression performed with a DRX9000 TM device on pain, functionality, depression, and quality of life in patients with low back pain associated with. Turkish J Phys Med Rehabil. 2018;64:17-27.

45. Mobeen A, Javed M, Sajjad AG et al. Effect of spinal decompression with and without segmental mobilization in patients with posterolateral lumbar disc protrusion. Rawal Med J. 2018;43(2):294-97.

46. López J. Effectiveness of maintained resonant oscillations in the treatment of acute lumbar disc hernia. A new manual therapy approach. Man Ther. 2016 Sep;100:e106-07.

47. Satpute K, Hall T, Bisen R et al. The effect of spinal mobilization with leg movement in patients with lumbar radiculopathy - a double-blind randomized controlled trial. Arch Phys Med Rehabil. 2019;100:828-36.

48. Kiran R, Mohanty P, Pattnaik M. Thoracic mobilisation and periscapular soft tissue manipulations in the management of chronic Prolapsed Intervertebral Disc (PIVD)-An innovative manual therapy approach. Australas Med J. 2017;10:838-47.

49. Pettine K, Suzuki R, Sand T et al. Treatment of discogenic back pain with autologous bone marrow concentrate injection with minimum two year follow-up. Int Orthop. 2016;40:135-40.

50. Tuakli-Wosornu YA, Terry A, Boachie-Adjei K et al. Lumbar intradiskal platelet-rich plasma (PRP) injections: a prospective, double-blind, randomized controlled study. PM R. 2016;8:1-10.

51. Basso $M$, Cavagnaro $L$, Zanirato $A$ et al. What is the clinical evidence on regenerative medicine in intervertebral disc degeneration? Musculoskelet Surg. 2017;101:93-104. 
52. Levi D, Horn S, Tyszko S et al. Intradiscal platelet-rich plasma injection for chronic discogenic low back pain: preliminary results from a prospective trial. Pain Med. 2016;17:1010-22.

53. Wankhade UG, Umashankar MK, Reddy BJ. Functional Outcome of Lumbar Discectomy by Fenestration Technique in Lumbar Disc Prolapse - Return to Work and Relief of Pain. J Clin Diagnostic Res JCDR. 2016;10:RC09.

54. Bai J, Zhang W, Wang $Y$ et al. Application of transiliac approach to intervertebral endoscopic discectomy in L5/S1 intervertebral disc herniation. Eur J Med Res. 2017;22:4-13.

55. Tonosu J, Oshima Y, Shiboi R et al. Consideration of proper operative route for interlaminar approach for percutaneous endoscopic lumbar discectomy. J Spine Surg. 2016;2:281-88.

56. Wang SJ, Chen BH, Wang P et al. The effect of percutaneous endoscopic lumbar discectomy under different anesthesia on pain and immunity of patients with prolapse of lumbar intervertebral disc. Eur Rev Med Pharmacol Sci. 2017;21:2793-99.

57. Phan K, Xu J, Schultz K et al. Full-endoscopic versus microendoscopic and open discectomy: a systematic review and meta-analysis of outcomes and complications. Clin Neurol Neurosurg. 2017;154:1-12.

58. Dutta A, Agarwala V, Daolagupu AK et al. Outcome of one level instrumented posterior lumbar interbody fusion in indicated cases of prolapsed intervertebral disc ( PIVD ) - A clinical study. Int J Orthop Sci. 2017;3:784-88.

59. Nikoobakht M, Yekanineajd MS, Pakpour AH et al. Plasma disc decompression compared to physiotherapy for symptomatic contained lumbar disc herniation: A prospective randomized controlled trial. Neurol Neurochir Pol. 2016;50:24-30.

60. Puvanesarajah $\mathrm{V}$, Hassanzadeh $\mathrm{H}$. The true cost of a dural tear: medical and economic ramifications of incidental durotomy during lumbar discectomy in elderly Medicare beneficiaries. Spine (Phila Pa 1976). 2017;42:770-76.

61. Murphy ME, Hakim JS, Kerezoudis P et al. Micro vs. macrodiscectomy: Does use of the microscope reduce complication rates? Clin Neurol Neurosurg. 2017;152:28-33.

62. Kotil K. Closed drainage versus non-drainage for single-level lumbar disc surgery: relationship between epidural hematoma and fibrosis. Asian Spine J. 2016;10:1072-78.

63. Qin R, Liu B, Hao J et al. Percutaneous Endoscopic Lumbar Discectomy Versus Posterior Open Lumbar Microdiscectomy for the Treatment of Symptomatic Lumbar Disc Herniation: A Systemic Review and Meta-Analysis. World Neurosurg. 2018;120:352-62.

Conflict of interest: none declared Financial support: none declared 